\title{
Profil Kemampuan Pemecahan Masalah Siswa SMA pada Materi Fluida Statis
}

\author{
Ernila Siringo Ringo ${ }^{1}$, Sentot Kusairi ${ }^{1}$, Eny Latifah ${ }^{1}$ \\ ${ }^{1}$ Pendidikan Fisika-Universitas Negeri Malang
}

\begin{tabular}{|c|c|}
\hline INFO ARTIKEL & ABSTRAK \\
\hline Riwayat Artikel: & $\begin{array}{l}\text { Abstract: This research was aimed to analyze the profile of students' ability to solve } \\
\text { static fluid problems. The survey research involved } 70 \text { XII students of Malang State }\end{array}$ \\
\hline Diterima: 25-01-2019 & High School 4. The research instrument was in the form of three problem solving \\
\hline Disetujui: 14-02-2019 & questions in the form of a description. The results showed the percentage of students in \\
\hline Kata kunci: & $\begin{array}{l}\text { high at } 69 \% \text {, so that students' overall problem solving abilities were classified as low. In } \\
\text { this study, a number of student difficulties were still found, one of which was about the }\end{array}$ \\
\hline $\begin{array}{l}\text { problem solving skill; } \\
\text { static fluid; } \\
\text { kemampuan pemecahan masalah; }\end{array}$ & $\begin{array}{l}\text { magnitude that affected the buoyancy force of objects in the fluid primarily on the } \\
\text { problems of Archimedes' Law. Innovative learning efforts are needed to improve } \\
\text { students' ability to solve problems. }\end{array}$ \\
\hline
\end{tabular}

\begin{abstract}
Abstrak: Penelitian ini bertujuan untuk menganalisis profil kemampuan siswa dalam memecahkan permasalahan fluida statis. Penelitian survei ini melibatkan 70 siswa kelas XII SMA Negeri 4 Malang. Instrumen penelitian berupa tiga butir soal pemecahan masalah berbentuk uraian. Hasil penelitian menunjukkan persentase siswa kategori expert masih rendah yaitu sebesar $31 \%$ dan siswa kategori novice cukup tinggi sebesar $69 \%$, sehingga kemampuan pemecahan masalah siswa secara keseluruhan tergolong rendah. Pada penelitian ini, beberapa kesulitan siswa masih ditemukan salah satunya mengenai besaran yang memengaruhi gaya apung benda dalam fluida utamanya pada permasalahan Hukum Archimedes. Perlu upaya pembelajaran inovatif untuk meningkatkan kemampuan siswa dalam memecahkan masalah.
\end{abstract}

\author{
Alamat Korespondensi: \\ Ernila Siringo Ringo \\ Pendidikan Fisika \\ Universitas Negeri Malang \\ Jalan Semarang 5 Malang \\ E-mail: ernilasr94@gmail.com
}

Fluida statis yang meliputi konsep tekanan hidrostatis, Hukum Pascal, dan Hukum Archimedes banyak diaplikasikan dalam kehidupan sehari-hari, namun siswa masih mengalami kesulitan (Kusairi dkk., 2017; Minogue \& Borland, 2015; Radovanović \& Sliško, 2013). Kesulitan yang dialami siswa yakni menentukan besar tekanan hidrostatis suatu titik pada posisi yang berbeda dan menganggap besar tekanan hidrostatis benda dalam fluida dipengaruhi oleh luas penampang dan bentuk bejana (Goszewski dkk., 2013; Loverude dkk., 2010). Siswa juga menganggap bahwa tekanan pada piston besar lebih besar daripada tekanan pada piston kecil (Chen dkk., 2013). Terkait Hukum Archimedes, siswa sulit membedakan antara massa benda dengan volume benda, sehingga siswa menganggap bahwa besar gaya apung benda dalam fluida dipengaruhi oleh massa benda tersebut (Bunyamin \& Phang, 2012; Çepni \& Şahin, 2012; Koes dkk., 2018; Wong dkk., 2010). Kesulitan-kesulitan yang dialami siswa disebabkan ketidakmampuan siswa dalam mengidentifikasi dan menyesuaikan konteks permasalahan yang diberikan dengan konsep-konsep dan prinsip-prinsip fisika yang tepat (Ding, dkk., 2011; Leak dkk., 2017; Lin \& Singh, 2015). Kesulitan-kesulitan yang masih dialami siswa berakibat rendahnya kemampuan siswa dalam menyelesaikan suatu permasalahan.

Purwanto \& Yuliati (2017) menunjukkan pemecahan masalah siswa masih tergolong rendah dengan rata-rata sebesar 48,88 dari skala skor 0 - 100. Penelitian lainnya juga menemukan bahwa nilai kemampuan pemecahan masalah siswa yang termasuk kategori baik kurang dari 50\% dan selebihnya masih kategori rendah (Purnamasari dkk., 2018). Oleh karena itu, siswa dituntut untuk memiliki kemampuan memecahkan masalah yang baik berdasarkan teori dan konsep yang relevan agar mampu menyelesaikan berbagai permasalahan pada fluida statis (Adams \& Wieman, 2015; Ding dkk., 2011). Kemampuan pemecahan masalah siswa dapat diketahui melalui lima tahapan, meliputi useful description, physics approach, spesific application of physics, mathematical procedure, dan logical progression. Kemampuan pemecahan masalah siswa terdiri dari kategori expert dan novice berdasarkan alternatif penyelesaian masalah mandiri siswa (Docktor dkk., 2016; Hull dkk., 2013; Walsh dkk., 2007). 
Siswa kategori novice hanya berlandaskan matematis dalam menyelesaikan masalah dan tidak menerapkan konsepkonsep yang bermakna dan sesuai. Siswa kategori expert, mengidentifikasi variabel yang berpengaruh pada masalah yang diberikan, menghubungkan dengan prosedur matematis dan mempertimbangkan teori, konsep, hukum, prinsip yang mendasari permasalahan, menganalisis dan menyelesaikan dengan konsep yang tepat (Adams \& Wieman, 2015; Ding dkk., 2011; J. Docktor \& Heller, 2009; Leak dkk., 2017).

Berdasarkan uraian di atas, maka dilakukan suatu analisis tentang profil kemampuan pemecahan masalah siswa untuk mengetahui kesulitan-kesulitan yang dialami pada fluida statis. Dengan kata lain, penelitian ini bertujuan untuk mendeskripsikan profil dan kesulitan siswa. Hal ini penting dilakukan agar para pendidik dapat merancang pembelajaran yang tepat untuk melatih dan meningkatkan kemampuan pemecahan masalah siswa sehingga siswa tidak akan mengalami kesulitan memecahkan berbagai permasalahan fisika.

\section{METODE}

Penelitian ini menggunakan metode survei dengan subjek siswa kelas XII MIPA di SMA Negeri 4 Malang sebanyak 70 siswa. Instrumen tes yang digunakan berupa tiga soal pemecahan masalah berbentuk uraian yang sudah divalidasi oleh dua dosen ahli. Rubrik penilaian jawaban siswa mengacu pada rubrik Docktor dkk. (2016) dengan rentang skor yang ditetapkan pada penelitian ini adalah skor 0 sampai 4 untuk masing-masing indikator pada setiap soal dengan skor maksimum 4. Pemberian skor 0 jika tidak menuliskan solusi, skor 1 solusi yang dibuat salah, skor 2 sebagian solusi yang dibuat berisi kesalahan dan sebagian benar, skor 3 solusi yang dibuat sudah tepat namun masih ada kesalahan sedikit, dan skor 4 solusi yang dibuat tepat dan lengkap. Profil kemampuan siswa dalam memecahkan masalah akan dianalisis pada lima indikator pemecahan masalah, meliputi useful description, physics approach, specific application of physics, mathematical procedure, dan logical progression, kemudian dikelompokkan pada kategori expert dan novice, seperti ditunjukkan pada Tabel 1 (Docktor \& Heller, 2009; Docktor dkk., 2016; Hull dkk., 2013; Lin \& Singh, 2015).

Tabel 1. Pengkategorian Kriteria Siswa Expert dan Novice

\begin{tabular}{|c|c|c|c|}
\hline \multirow{2}{*}{ No } & \multirow{2}{*}{ Indikator } & \multicolumn{2}{|c|}{ Kriteria } \\
\hline & & Expert & Novice \\
\hline 1. & $\begin{array}{l}\text { Useful } \\
\text { Description }\end{array}$ & $\begin{array}{l}\text { Mendeskripsikan masalah dengan merangkum } \\
\text { informasi yang relevan dalam bentuk simbolis dari } \\
\text { variabel yang berpengaruh, gambar, dan verbal secara } \\
\text { tepat dan lengkap }\end{array}$ & $\begin{array}{l}\text { Mendeskripsikan masalah dengan menuliskan variabel } \\
\text { yang berpengaruh belum lengkap, sebagian hilang atau } \\
\text { berisi kesalahan }\end{array}$ \\
\hline 2. & $\begin{array}{l}\text { Physics } \\
\text { Approach }\end{array}$ & $\begin{array}{l}\text { Menuliskan pendekatan fisika yang berguna sebagai } \\
\text { solusi pada masalah dengan tepat dan lengkap }\end{array}$ & $\begin{array}{l}\text { Sebagian pendekatan fisika yang dituliskan belum tepat, } \\
\text { masih salah, bahkan melewati langkah ini }\end{array}$ \\
\hline 3. & $\begin{array}{l}\text { Specific } \\
\text { Application of } \\
\text { Physics }\end{array}$ & $\begin{array}{l}\text { Memilih persamaan yang relevan sebagai solusi } \\
\text { dengan mengaplikasikannya sesuai permasalahan } \\
\text { dengan tepat dan lengkap }\end{array}$ & $\begin{array}{l}\text { Hanya menuliskan persamaan umumnya tanpa } \\
\text { mengaplikasikannya sesuai permasalahan, belum } \\
\text { lengkap, masih berisi kesalahan, dan bahkan tidak } \\
\text { menuliskannya. }\end{array}$ \\
\hline 4. & $\begin{array}{l}\text { Mathematical } \\
\text { Procedures }\end{array}$ & $\begin{array}{l}\text { Melakukan perhitungan sesuai prosedur hingga } \\
\text { memeroleh hasil yang tepat dan lengkap }\end{array}$ & $\begin{array}{l}\text { Memproses dan memeroleh data masih belum tepat, } \\
\text { belum lengkap, bahkan tidak melakukan perhitungan } \\
\text { sama sekali }\end{array}$ \\
\hline 5. & $\begin{array}{l}\text { Logical } \\
\text { Progression }\end{array}$ & $\begin{array}{l}\text { Proses penyelesaian yang digunakan jelas, fokus, dan } \\
\text { tepat sehingga mampu membuktikan kesesuaian hasil } \\
\text { yang diperoleh dengan solusi yang digunakan }\end{array}$ & $\begin{array}{l}\text { Proses penyelesaian yang digunakan tidak jelas, tidak } \\
\text { fokus, hanya menuliskan kembali hasil yang diperoleh, } \\
\text { dan tidak mengaitkan hasil terhadap proses yang } \\
\text { digunakan sebagai solusi }\end{array}$ \\
\hline
\end{tabular}

\section{HASIL}

Hasil analisis deskriptif statistik mengenai skor rata-rata kemampuan pemecahan masalah siswa pada materi fluida statis ditunjukkan pada Tabel 2.

Tabel 2. Deskriptif Statistik Skor Rata-Rata Kemampuan Pemecahan Masalah Siswa

\begin{tabular}{cc}
\hline Deskriptif Statistik & Nilai \\
\hline $\mathrm{N}$ & 70 \\
Mean & 2,03 \\
Nilai Maksimum & 3 \\
Nilai Minimum & 0 \\
Range & 3 \\
Standar Deviasi & 0,85 \\
\hline
\end{tabular}


Hasil perhitungan di atas menunjukkan skor rata-rata pemecahan masalah dari 70 siswa adalah sebesar 2,03 dari rentang skor 0 sampai 4. Secara garis besar, siswa masih dalam kategori novice. Hal ini ditunjukkan dari rentang skor keseluruhan jawaban siswa pada ketiga soal dalam bentuk diagram, seperti pada Gambar 1.

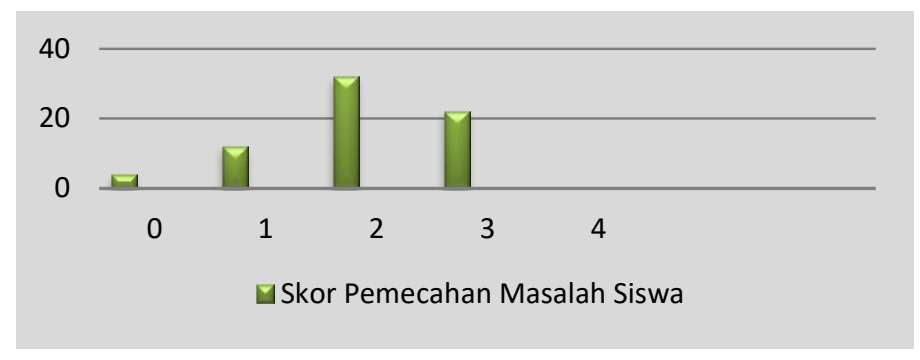

\section{Gambar 1. Skor Keseluruhan Pemecahan Masalah Siswa}

Siswa kategori novice berada pada skor 0 sampai 2 dan siswa expert berada pada skor 3 sampai 4 yang ditentukan berdasarkan kriteria jawaban siswa pada permasalahan disoal. Siswa kategori novice, hanya menuliskan hubungan besaranbesaran yang diketahui secara kuantitatif dan tidak bermakna, sedangkan siswa expert meninjau permasalahan secara kualitatif dan bermakna. Setelah memahami permasalahan yang diberikan, siswa expert mampu menuliskan pendekatan fisika yang tepat dan memilih persamaan yang akan digunakan untuk menyelesaikan masalah, tetapi siswa novice hanya menuliskan persamaan fisika saja tanpa memahami konsep fisika yang mendasarinya. Penyelesaian masalah siswa expert lebih kuat dengan strategi matematika dan evaluasi jawaban yang tepat, sedangkan siswa novice kurang mampu mengoperasikan setiap data yang diketahui dari permasalahan (Adams \& Wieman, 2015; Docktor \& Heller, 2009; Docktor dkk., 2016; Docktor, Strand, Mestre, \& Ross, 2015; Leak dkk., 2017). Berdasarkan data keseluruhan skor dan jawaban siswa tersebut, diperoleh persentase siswa dalam kategori expert sebesar 31\% dan siswa kategori novice sebesar 69\%. Selain itu, kategori siswa expert dan novice dapat dikelompokkan berdasarkan data sebaran skor siswa pada setiap butir soal pemecahan masalah yakni, tekanan hidrostatis pada soal nomor 1, hukum Pascal soal nomor 2, dan soal nomor 3 terkait permasalahan hukum Archimedes. Hal ini ditunjukkan dalam bentuk diagram seperti pada Gambar 2.

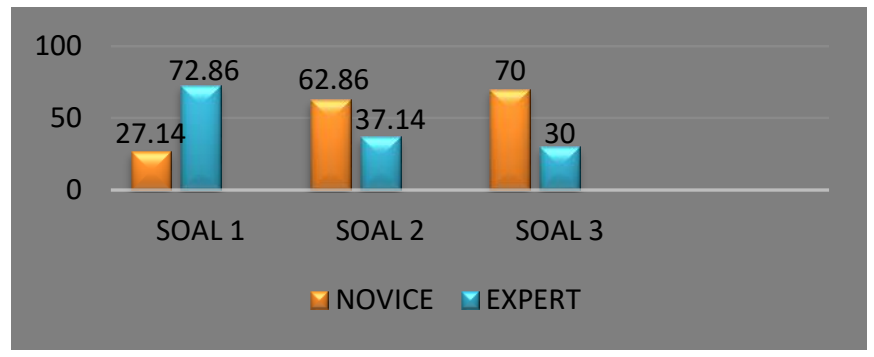

\section{Gambar 2. Kategori Kemampuan Pemecahan Masalah Siswa pada Setiap Soal}

Gambar 2 menunjukkan persentase siswa expert pada soal nomor 1 lebih tinggi daripada siswa novice sehingga dapat dikatakan kebanyakan siswa sudah mampu menyelesaikan permasalahan terkait tekanan hidrostatis. Hal berbeda ditemukan pada soal nomor 2 dan nomor 3 yang memperoleh persentase siswa novice lebih tinggi daripada siswa expert, sehingga rata-rata siswa masih belum mampu menyelesaikan dengan baik setiap permasalahan terkait Hukum Pascal dan Hukum Archimedes. Hal ini menandakan, masih banyak siswa yang mengalami kesulitan mengenai Hukum Pascal dan Hukum Archimedes dan sebagian siswa juga mengalami kesulitan pada tekanan hidrostatis. Adapun analisis jawaban siswa novice dan expert dalam memecahkan masalah fluida statis pada setiap butir soal dan setiap indikator pemecahan masalah, sebagaimana ditunjukkan pada Gambar 3.

\section{Kemampuan Pemecahan Masalah pada Tekanan Hidrostatis}

1. Carles, Doni, dan Eko adalah siswa SMAN 4 Malang yang sedang mengikuti Studi Kenal Lingkungan (SKAL) ke Wisata Bahari Lamongan. Mereka ingin membuktikan hukum pokok hidrostatis ketika berenang. Carles dan Doni memutuskan untuk berenang di laut, sementara Eko lebih memilih berenang di kolam renang yang berisi air tawar. Setelah selesai berenang mereka berkumpul untuk membahas tentang kedalaman saat mereka berenang dan tekanan hidrostatis yang dirasakan.

(Keterangan: Kedalaman mereka berenang yaitu 3 meter, $\rho_{\text {air laut }}=1.025 \mathrm{~kg} / \mathrm{m}^{3}$, dan $\rho_{\text {air }}=1.000 \mathrm{~kg} / \mathrm{m}^{3}$ ). 
Berikut contoh jawaban dari siswa expert dan novice dalam menyelesaikan permasalahan pada soal nomor 1 di atas dapat dilihat pada Gambar 4.

\section{Useful Description :}

Diketahui :

$\rho_{\text {air }}=1.000 \mathrm{~kg} / \mathrm{m}^{3} ; \rho_{\text {air laut }}=1.025 \mathrm{~kg} / \mathrm{m}^{3} ; \mathrm{h}_{\text {air }}=$

$\mathrm{h}_{\text {air laut }}=3 \mathrm{~m}$

Carles \& Doni = Berenang di laut ; Eko = berenang di air tawar

$\mathrm{h}=\mathrm{h}_{\mathrm{C}}=\mathrm{h}_{\mathrm{D}}=\mathrm{h}_{\mathrm{E}}=3 \mathrm{~m}$

Ditanya :

Hubungan antara $\rho$ dan h dengan P (tekanan hidrostatis)?

Physics Approach :

Bahwa tekanan hidrostatis ditentukan oleh rapat massa atau massa jenis $(\rho)$ dan kedalaman titik partikel/ benda dari permukaan (h)

$\rightarrow$ semakin besar massa jenis $(\rho)$ dan kedalaman (h), semakin

besar pula tekanan hidrostatisnya (P) dan sebaliknya.

Specific Application of Physics :

Dalam tekanan hidrostatis dirumuskan :

$\mathrm{P}=\rho \cdot g \cdot h$, massa jenis $(\rho)$; percepatan gravitasi $(\mathrm{g})$;

kedalaman (h)

Sedangkan dalam kasus tersebut digunakan rumus sebagai berikut :

$P_{\text {air tawar }}=\rho_{\text {air }} \cdot g \cdot \mathrm{h}_{\mathrm{E}} ; \mathrm{h}_{\mathrm{E}}=$

kedalaman Eko berenang di air tawar

$P_{\text {air laut }}=\rho_{\text {air laut }} \cdot g \cdot \mathrm{h}_{\mathrm{C}} ; \mathrm{h}_{\mathrm{C}}=$

; kedalaman Carles berenang di air laut $=\mathrm{h}_{D o n i}$

Mathematical Procedures :

$P_{\text {air tawar }}=\rho_{\text {air }} \cdot g \cdot \mathrm{h}_{\mathrm{E}}$

$P_{\text {air tawar }}=1.000 \mathrm{~kg} / \mathrm{m}^{3} .10 \mathrm{~m} / \mathrm{s}^{2} .3 \mathrm{~m}=30.000 \mathrm{~N} / \mathrm{m}^{2}$

Tekanan yang dialami Eko saat berenang di kolam berenang adalah $30.000 \mathrm{~N} / \mathrm{m}^{2}$.

$P_{\text {air laut }}=\rho_{\text {air laut }} \cdot g \cdot \mathrm{h}_{\mathrm{C}}$

$P_{\text {air laut }}=1.025 \mathrm{~kg} / \mathrm{m}^{3} .10 \mathrm{~m} / \mathrm{s}^{2} \cdot 3 \mathrm{~m}=30.750 \mathrm{~N} / \mathrm{m}^{2}$

Tekanan yang dialami Carles dan Doni saat berenang di kolam

berenang adalah sama sebesar $30.750 \mathrm{~N} / \mathrm{m}^{2}$

Logical Progression :

Kesimpulannya, pada kasus Carles, Doni, dan Eko dapat dipecahkan dengan konsep tekanan hidrostatis, sedangkan tekanan hidrostatis sendiri dipengaruhi oleh massa jenis fluida dan

kedalaman, sehingga semakin besar massa jenisnya semakin besar tekanannya. Pada kedalaman yang sama dan massa jenis berbeda, maka pada kasus tersebut tekanan terbesar dialami oleh Carles dan Doni saat berenang di air laut.

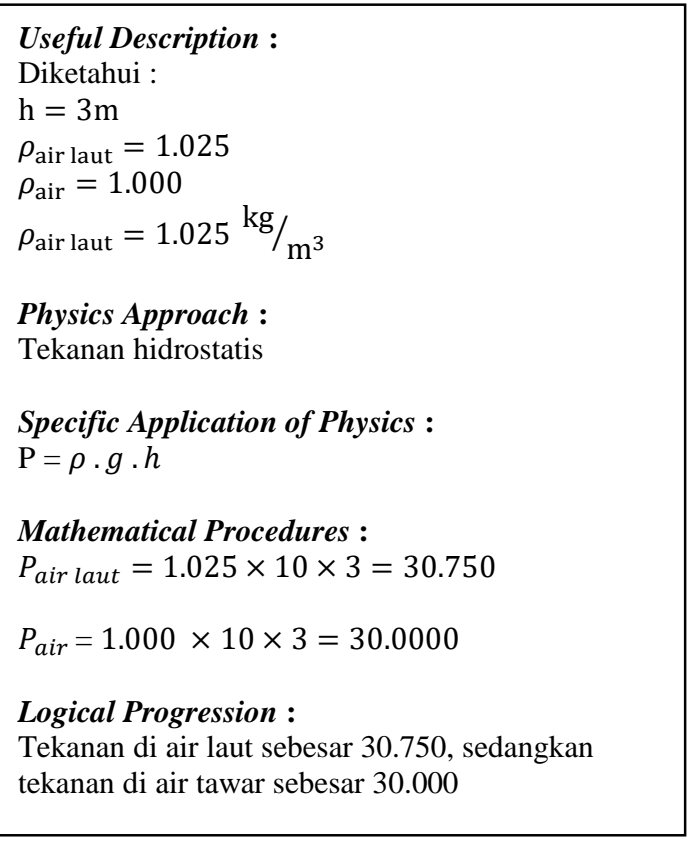

(b)

(a)

\section{Gambar 4. Contoh Jawaban Siswa pada Soal 1 (a) Siswa Expert ; (b) Siswa Novice}

Indikator usefull description menunjukkan siswa expert mampu mendeskripsikan permasalahan secara lengkap dan bermakna pada setiap variabel yang diketahui, sedangkan siswa novice hanya menuliskan beberapa variabel tanpa satuan dan masih sulit memahami masalah di soal yang harus dipecahkan. Indikator physics approach menunjukkan, siswa expert sudah memahami konsep dari tekanan hidrostatis sebagai dasar untuk memecahkan masalah pada soal, sedangkan sebagian siswa novice hanya menuliskan judul sub materinya karena belum memahami konsep tekanan hidrostatis secara kualitatif yang berkaitan dengan aplikasi dalam kehidupan sehari-hari.

Indikator Specific Application of Physics menunjukkan siswa expert mampu memahami konsep tekanan hidrostatis secara kuantitatif dengan menuliskan persamaannya dan mengaplikasikannya sesuai permasalahan secara lengkap, sedangkan siswa novice hanya menuliskan persamaan tanpa mengaitkan dengan masalah di soal sehingga kurang bermakna. Siswa yang memiliki pengetahuan dan konsep yang luas akan memudahkan siswa menentukan solusi yang akan dipakai untuk memecahkan masalah (Docktor \& Mestre, 2014; Kuczmann, 2017; Lin \& Singh, 2015; Ryan dkk., 2016). 
Indikator Mathematical Procedure menunjukkan siswa expert dan novice mampu melakukan perhitungan matematis dengan benar, tetapi siswa novice masih tidak menuliskan satuan dari besaran fisika dan tidak menjelaskan pengaruh dari nilai yang diperoleh terhadap masalah yang ditawarkan. Indikator Logical Progression menunjukkan siswa expert mampu menyelesaikan permasalahan dengan lengkap dan membuktikan kebenaran konsep yang digunakan terhadap hasil yang diperoleh, yaitu besar tekanan hidrostatis dipengaruhi oleh massa jenis zat fluida, percepatan gravitasi, dan kedalaman benda di dalam fluida berdasarkan aplikasi kehidupan sehari-hari pada saat berenang, seperti pada soal nomor 1. Selain itu, siswa novice diketahui hanya menuliskan kembali nilai dari tahap sebelumnya tanpa memaknai keseluruhan tahap. Hal ini disebabkan oleh kesulitan siswa menentukan besaran yang memengaruhi tekanan hidrostatis dan sulit mengaplikasikannya pada peristiwa yang terjadi dalam kehidupan sehari-hari (Argaw, 2017; Bunyamin \& Phang, 2012; Goszewski dkk., 2013; Koes dkk., 2018; Minogue \& Borland, 2015).

\section{Kemampuan Pemecahan Masalah pada Hukum Pascal}

2. Pak Budi ingin membuat media ajar sederhana berupa bejana berhubungan yang mempunyai 3 rongga yang ditutup oleh penghisap seperti gambar di bawah. Apabila bekerja gaya sebesar $10 \mathrm{~N}$ untuk menekan penghisap pada rongga terkecil yaitu $\mathrm{A}$, maka bagaimana rancangan luas penampang ketiga rongga yang tepat yang harus di rancang oleh Pak Budi, agar dapat mengangkat beban seberat $50 \mathrm{~N}$ dan $100 \mathrm{~N}$ ?

\section{Gambar 5. Soal 2 Pemecahan Masalah}

Berikut contoh jawaban dari siswa expert dan novice dalam menyelesaikan permasalahan pada soal nomor 2 di atas dapat dilihat pada Gambar 6.

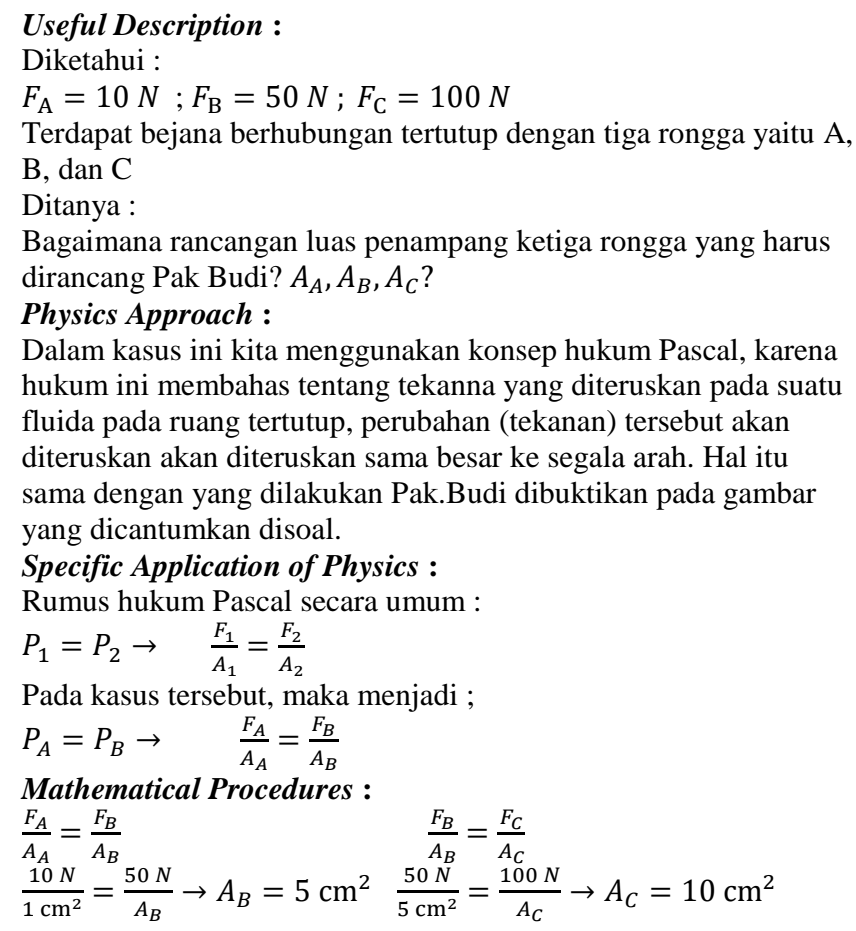

Logical Progression :

Dalam kasus ini digunakan hukum Pascal karena terdapat tekanan dalam wadah tertutup yang sama besar pada penghisap A, B, C, sehingga perbandingan luas penampang yang sesuai untuk dirancang oleh Pak.Budi adalah $A_{A}: A_{B}: A_{C}$ yaitu $1: 5: 10$ Rancangan ini akan mampu mengangkat beban $50 \mathrm{~N}$ dan $100 \mathrm{~N}$ sekalipun luas penampang rongga A lebih kecil, tetapi gaya yang diberikan tidak besar. karena tekanan sama besar.

\section{Useful Description :}

$F_{\mathrm{C}}=100 \mathrm{~N} ; F_{\mathrm{B}}=50 \mathrm{~N} ; F_{\mathrm{A}}=10 \mathrm{~N}$

\section{Physics Approach :}

Berdasarkan hukum Pascal yaitu membandingkan tekanan hidrolisis

Specific Application of Physics : $P=\frac{F}{A}$

Mathematical Procedures :

$\frac{F_{1}}{A_{1}}=\frac{F_{2}}{A_{2}} \rightarrow \frac{10}{A_{1}}=\frac{50}{A_{2}} \rightarrow A_{2}=5 A_{1}$
$\frac{F_{1}}{A_{1}}=\frac{F_{3}}{A_{3}} \rightarrow \frac{10}{A_{1}}=\frac{100}{A_{2}} \rightarrow A_{3}=10 A_{1}$

\section{Logical Progression :}

Jadi, luas penampang untuk angkat beban $50 \mathrm{~N}$ yaitu $A_{2}=5 A_{1}$ dan untuk angkat beban $100 \mathrm{~N}$ yaitu $10 A_{1}$.

Semakin besar luas penampangnya, semakin besar tekanannya dan semakin besar gaya yang harus kita berikan untuk mengangkat beban besar.

(a)

Gambar 6. Contoh Jawaban Siswa Pada Soal 2 (a) Siswa Expert ; (b) Siswa Novice 
Indikator usefull description menunjukkan, siswa expert dan novice sudah mampu mendeskripsikan besaran yang diketahui dengan menambah keterangan setiap variabelnya, hanya saja siswa novice masih tidak menuliskan variabel yang menjadi permasalahan untuk dipecahkan. Indikator physics approach menunjukkan, siswa expert menjelaskan dan mengaitkan konsep Hukum Pascal terhadap permasalahan dengan tepat, sedangkan siswa novice hanya menuliskan judul sub materinya. Tahap ini juga terlihat bahwa konsep siswa sebagai dasar untuk memecahkan masalah mengenai Hukum Pascal masih rendah, hal ini dikarenakan siswa belum mengenal aplikasi-aplikasi dalam kehidupan sehari-hari yang menggunakan prinsip Pascal seperti pompa hidrolik dan dongkrak hidrolik. Apabila siswa terbiasa mengetahui prinsip kerja suatu alat yang menggunakan prinsip Pascal, akan membantu siswa memecahkan masalah terkait Hukum Pascal (Chen dkk., 2013; Goszewski dkk., 2013; Kuczmann, 2017; Ozcan \& Gercek, 2015). Indikator Specific Application of Physics menunjukkan persamaan yang dipilih oleh siswa expert sudah sesuai untuk digunakan dalam memecahkan masalah Hukum Pascal, tetapi siswa novice hanya menuliskan persamaan dasar dari tekanan. Siswa novice mengalami kesulitan dalam menentukan persamaan matematis yang akan digunakan sebagai solusi dari permasalahan tersebut (Chen dkk., 2013; Goszewski dkk., 2013).

Indikator Mathematical Procedure menunjukkan perhitungan matematis siswa expert dilakukan dengan prosedur yang tepat hingga menemukan jawaban yang benar, sedangkan sebagian siswa novice melakukan perhitungan belum sampai tahap memperoleh hasil karena masih ada variabel yang belum diaplikasikan. Indikator Logical Progression menunjukkan, siswa expert sudah membuktikan prinsip Pascal yang digunakan sebagai solusi dalam merancang luas penampang bejana berhubungan tersebut dari hasil yang diperoleh, sedangkan siswa novice hanya menuliskan kembali hasil yang diperoleh dengan kata-kata tanpa menyimpulkannya terhadap prinsip Pascal yang bekerja pada bejana tertutup. Hal ini menunjukkan bahwa siswa novice masih sulit memaknai pengaruh dari gaya-gaya yang bekerja pada rancangan tersebut dan sebagian siswa masih menganggap tekanan pada penghisap besar lebih besar karena dipengaruhi luas penampang yang dimilikinya, serta gaya yang diberikan pada penghisap kecil harus lebih besar agar dapat mengangkat beban pada penghisap besar.

\section{Kemampuan Pemecahan Masalah pada Hukum Archimedes}

\section{Gambar 7. Soal 3 Pemecahan Masalah}

Indikator usefull description menunjukkan, tidak ditemukan kesulitan siswa expert dan novice dalam mendeskripsikan variabel-variabel pada permasalahan diatas, hanya saja masih ada yang belum menuliskan satuan dari besaran Fisika. Indikator physics approach menunjukkan, siswa expert dan novice mampu menjelaskan pendekatan yang sesuai pada permasalahan gaya angkat benda sebagai dasar teori dalam menentukan aplikasi yang akan digunakan. Namun, ada beberapa siswa novice langsung menuliskan persamaan gaya apung tanpa berangkat dari prinsip gaya apung pada peristiwa terapung, melayang, dan tenggelam. Indikator Specific Application of Physics menunjukkan, siswa expert mampu memahami konsep gaya apung secara kuantitatif dengan menuliskan persamaannya dan mengaplikasikannya sesuai permasalahan secara lengkap, sedangkan siswa novice masih ditemukan kesalahan dalam mengaplikasikan persamaan gaya apung. Siswa novice sulit membedakan prinsip gaya apung dengan konsep tekanan hidrostatis sehingga siswa menuliskan persamaan yang serupa pada gaya apung.

Indikator Mathematical Procedure menunjukkan prosedur perhitungan siswa expert sudah tepat dalam mengaplikasikan persamaan umum gaya apung dan menyesuaikannya sesuai permasalahan disoal, sedangkan siswa novice melakukan perhitungan hanya berdasarkan persamaan umumnya. Siswa novice juga masih sulit menganalisis variabel yang memengaruhi gaya apung dan sulit menentukan besar volume benda yang tercelup dalam zat cair karena menganggap bahwa massa benda sama dengan volume benda. Indikator Logical Progression menunjukkan, siswa expert mampu menyelesaikan permasalahan dengan lengkap dan membuktikan kebenaran dari prinsip benda terapung, melayang, dan tenggelam yang digunakan terhadap hasil yang diperoleh yaitu benda akan tenggelam jika massa jenis benda lebih besar daripada massa jenis zat cair berdasarkan aplikasi kehidupan sehari-hari pada jembatan ponton seperti pada soal nomor 3. Siswa novice melakukan kesalahan dalam menyelesaikan permasalahan di soal sehingga kesimpulan yang dituliskan tidak sesuai. Berikut contoh jawaban dari siswa expert dan novice dalam menyelesaikan permasalahan pada soal nomor 1 di atas dapat dilihat pada Gambar 8 . 


\section{Useful Description :}

Diketahui :

$\mathrm{m}_{\text {truk }}=3.000 \mathrm{~kg} ; \mathrm{V}_{\text {drum }}=0,3 \mathrm{~m}^{3} ; \mathrm{m}_{\text {drum }}=10 \mathrm{~kg}$

Jumlah drum $=10$ buah $; l_{\text {jembatan bambu }}=80 \mathrm{~m}$

Ditanya :

$\mathrm{w}_{\text {max }}$ yang boleh ditampung oleh jembatan ponton ketika seluruh bagian drum terbenam dalam air?

Physics Approach :

Dalam kasus ini kita menggunakan konsep gaya apung. Gaya apung dipengaruhi oleh massa jenis zat cair, percepatan gravitasi, dan volume fluida yang yang dipindahkan. Semakin besar ketiga faktor tersebut, maka semakin besar gaya apung yang dialami benda dalam zat cair.

Specific Application of Physics :

$F_{a}=\rho \cdot g \cdot V_{\text {dipindahkan }}$

Berdasarkan kasus, maka persamaan menjadi

$F_{\text {beban }}=F_{a}-F_{\text {drum }} \rightarrow F_{\text {beban }}=\rho \cdot g \cdot V_{\text {dipindahkan }}-$

$\mathrm{m}_{\mathrm{drum}} \cdot \mathrm{g}$

Mathematical Procedures :

$F_{\text {beban }}=\rho \cdot g \cdot V_{\text {dipindahkan }}-\mathrm{m}_{\text {drum }} \cdot \mathrm{g}$

$F_{\text {beban }}=1.000 \mathrm{~kg} / \mathrm{m}^{3} \cdot 10 \mathrm{~m} / \mathrm{s}^{2} \cdot 0,3 \mathrm{~m}^{3}-10 \mathrm{~kg} \cdot 10 \mathrm{~m} / \mathrm{s}^{2}=$ $2.900 \mathrm{~N}$

Beban yang sanggup ditahan oleh 10 drum pada jembatan ponton adalah

$F_{\text {beban }}=W_{\text {ditahan }} \rightarrow 2.900 N \times 10$ drum $=W_{\text {ditahan }} \rightarrow$ $29.000 N=W_{\text {ditahan }}$

Logical Progression :

Jika trus bermassa $3.000 \mathrm{~kg}$, maka berat truk sebesar $30.000 \mathrm{~N}$, sedangkan berat maksimal yang dapat ditahan 10 drum adalah $29.000 \mathrm{~N}$, maka jembatan ponton tersebut tidak akan sanggup mengangkat truk untuk lewat karena melebihi batas kemampuan untuk menahan beban di atasnya. Apabila truk tetap dipaksakan lewat, maka jembatan akan tenggelam dan truk pun ikut tenggelam. Supaya truk dapat lewat, maka beban pangan yang diangkutnya dikurangi.

\section{Useful Description :}

Diketahui :

Lebar sungai $=80 \mathrm{~m}$; Massa truk $=3.000 \mathrm{~kg}$

Volume drum $=0,3 \mathrm{~m}^{3} ;$ Massa drum $=10 \mathrm{~kg}$

Ditanya :

$\mathrm{w}_{\max }$ ?

Physics Approach :

Hukum archimedes, dimana benda yang

dicelupkan dalam air akan mengalami gaya apung yang dipengaruhi oleh massa benda yang tercelup, massa benda yang semakin kecil akan semakin

besar gaya apungnya sehingga tidak tenggelam.

Specific Application of Physics :

$F_{a}=\rho \cdot g \cdot h$

Mathematical Procedures:

$F_{a}=\rho \cdot g \cdot V=1.000 \cdot 10 \cdot 0,3=2.900 \mathrm{~N}$

Logical Progression :

Maka gaya apung jembatan ponton sebesar 2.900

$\mathrm{N}$ untuk menahan truk lewat

(b)

(a)

\section{Gambar 8. Contoh Jawaban Siswa Pada Soal 3 (a) Siswa Expert ; (b) Siswa Novice}

\section{PEMBAHASAN}

Berdasarkan data penelitian, kemampuan pemecahan masalah siswa masih dikatakan rendah dan termasuk dalam kategori novice. Hal ini terlihat dari skor rata-rata pemecahan masalah siswa sebesar 2,03 dari skala skor 0 sampai 4 dan jumlah presentasi siswa kategori novice lebih tinggi dibandingkan siswa kategori expert. Terdapat beberapa temuan dalam penelitian ini mengenai kesulitan-kesulitan siswa dalam melakukan proses pemecahan masalah dan kesalahan-kesalahan siswa dalam mengaplikasikan konsep fluida statis pada permasalahan yang diberikan. Siswa mengalami kesulitan pada konsep tekanan hidrostatis saat menjelaskan pengaruh massa jenis fluida yang berbeda terhadap tekanan yang dialami seseorang ketika berenang. Hal itu terlihat dari beberapa jawaban siswa yang belum mampu mengaitkan hasil yang diperoleh dengan pendekatan yang digunakan. Kesulitan ini juga ditemui pada penelitian Goszewski dkk. (2013) \& Minogue \& Borland (2015), menyatakan siswa sulit dalam menentukan konsep variabel tekanan hidrostatis pada bejana berhubungan tiga buah lubang dan berbeda bentuk. Padahal besar tekanan hidrostatis yang dialami suatu benda dalam fluida dipengaruhi oleh massa jenis fluida, percepatan gravitasi, dan kedalaman terhadap fluida sehingga semakin besar massa jenis fluida dan kedalaman fluida maka semakin besar pula tekanan yang dialami suatu titik dalam fluida (Loverude dkk., 2010; Serway dkk., 2010).

Kesulitan siswa juga ditemukan pada permasalahan Hukum Pascal, yakni siswa masih menganggap besar tekanan tidak sama pada setiap rongga bejana tertutup yang memiliki luas penampang yang berbeda-beda. Siswa juga menganggap bahwa gaya yang harus diberikan pada rongga kecil harus lebih besar daripada rongga besar untuk mengangkat beban pada rongga besar. Hal ini sejalan dengan penelitian Chen dkk. (2013) \& Goszewski dkk. (2013) yang menemukan bahwa siswa menganggap besar tekanan yang bekerja pada piston besar dan piston kecil berbeda, siswa kesulitan menentukan gaya yang bekerja pada piston yang memiliki beberapa cabang dan berbeda bentuk, dan menganggap gaya gravitasi dan kemiringan posisi piston yang memengaruhi besar tekanan yang diteruskan. 
Namun, dua kesulitan terakhir tersebut tidak ditemukan pada penelitian ini. Kesulitan tersebut dikarenakan siswa masih belum menguasai prinsip Pascal yang digunakan sebagai solusi, dimana pada bejana berhubungan yang tertutup tekanan yang diberikan pada zat cair akan diteruskan sama besar ke segala arah di setiap titik fluida (Serway dkk., 2010; Walker \& Halliday, 2011). Selain itu, pada permasalahan Hukum Archimedes masih ditemukan kesulitan siswa saat proses penyelesaian masalah dan memperoleh hasil, yang mana siswa hanya terpaku pada persamaan umum tanpa mengembangkan persamaan berdasarkan permasalahan yang diberikan sehingga hasil yang diperoleh tidak tepat. Siswa juga masih sulit memahami besaranbesaran yang memengaruhi gaya apung sehingga siswa masih menganggap bahwa yang memengaruhi gaya apung benda dalam fluida adalah massa benda. Kesulitan siswa lainnya ditemukan dalam memahami prinsip Archimedes pada peristiwa terapung, melayang, dan tenggelam, sehingga siswa masih ada yang menyimpulkan bahwa massa truk $3.000 \mathrm{~kg}$ mampu ditahan oleh jembatan ponton dengan berat maksimal ketahanannya 29.000 N. Hal ini menunjukkan siswa juga masih sulit membedakan antara massa dengan berat. Persoalan serupa juga ditemukan pada penelitian-penelitian sebelumnya (Bunyamin \& Phang, 2012; Chen dkk., 2013; Goszewski dkk., 2013; Minogue \& Borland, 2015; Radovanović \& Sliško, 2013). Prinsip benda terapung terjadi ketika massa jenis benda lebih besar daripada massa jenis fluida di posisi setimbang, sebaliknya untuk keadaan tenggelam yang membuat benda mengalami percepatan ke bawah. Sebuah benda yang terendam seluruhnya atau sebagian di dalam fluida mendapat gaya apung berarah ke atas yang besarnya adalah sama dengan berat fluida yang dipindahkan oleh benda. Oleh karena itu, gaya apung hanya ditentukan oleh jumlah volume air yang dipindahkan, bukan massa jenis benda, massa truk, posisi ataupun kedalaman (Serway dkk., 2010; Walker \& Halliday, 2011; Wong dkk., 2010).

Selain kesulitan siswa dalam memecahkan masalah berdasarkan pendekatan fisikanya, ditemukan pula beberapa siswa masih sering mengabaikan penulisan satuan dan besaran-besaran yang diketahui dan ditanya pada permasalahan. Terdapat pula beberapa siswa yang belum mengaitkan hasil yang diperoleh terhadap pendekatan fisika sehingga kemampuan siswa tersebut hanya sampai memperoleh hasil tanpa memaknainya. Hal ini masih ditemukan dari jawaban siswa pada ketiga soal pemecahan masalah yang diberikan (Ding dkk., 2011; Docktor dkk., 2015). Hasil penelitian sebelumnya menyatakan bahwa siswa seringkali kesulitan memecahkan masalah yang berkaitan dengan konsep-konsep fisika, baik masalah yang diberikan guru maupun yang berhubungan dengan dunia nyata di kehidupan sehari-hari (Gök \& Sỳlay, 2010; Walsh dkk., 2007; Yuliati \& Parno, 2018). Kesulitan-kesulitan siswa tersebut dipengaruhi oleh, masih jarangnya diterapkan suatu pembelajaran yang melatih dan mengasah kemampuan siswa dalam memecahkan masalah yang berhubungan dengan konseptual dan pengalaman kehidupan sehari-hari (Docktor dkk., 2015; Gök \& Sỳlay, 2010; Santos dkk., 2015). Oleh karena itu, beberapa rekomendasi dari penelitian sebelumnya sebagai solusi untuk membantu mengatasi permasalahan tersebut, Bell dkk. (2010) menyarankan untuk merancang pembelajaran yang dapat melatih siswa menyelidiki masalah-masalah fisika secara mandiri untuk mengintegrasikan pengetahuan yang dimiliki dan melatihkan soal-soal pemecahan masalah melalui model collaborative inquiry learning.

Penelitian yang dilakukan oleh Walsh dkk. (2007) menyarankan penerapan phenomenographic approach dan Yuliati \& Parno (2018) menyarankan penerapan phenomenon based learning, melalui pembelajaran ini dapat mengkondisikan siswa berdasarkan fenomena-fenomena, agar siswa mengerti makna dari apa yang mereka pelajari untuk diterapkan dalam memecahkan permasalahan pada kehidupan sehari-hari. Rekomendasi lainnya oleh Sujarwanto, Hidayat, \& Wartono (2014) dengan menerapkan modelling instruction yang mampu meningkatkan kemampuan pemecahan masalah fisika siswa, dengan mengonstruksi kemampuan siswa melalui pemodelan berupa diagram, grafik, gambar yang akan membantu siswa mengenali masalah berdasarkan konsep, membuat representasi dari masalah, dan evaluasi terhadap solusi dan konsep yang digunakan. Beberapa rekomendasi tersebut merupakan upaya yang disarankan peneliti dalam membantu siswa mengembangkan pengetahuannya untuk mengatasi dan mengurangi kesulitan-kesulitan dalam menyelesaikan masalah dan meningkatkan kemampuan pemecahan masalah fisika siswa (Adams \& Wieman, 2015; Bell dkk., 2010; Docktor \& Mestre, 2014; Ontario Ministry of Education, 2014; Urhahne dkk., 2009).

\section{SIMPULAN}

Berdasarkan hasil analisis data dan pembahasan menunjukkan bahwa kemampuan pemecahan masalah siswa SMA Negeri 4 Malang masih rendah walaupun telah menempuh pelajaran fluida statis. Hal tersebut dibuktikan dari capaian rata-rata skor keseluruhan pemecahan masalah siswa pada tes kemampuan pemecahan masalah hanya berada pada kriteria rendah. Rendahnya kemampuan siswa dalam memecahkan masalah juga ditunjukkan dari persentase siswa dalam kategori novice lebih tinggi daripada siswa dalam kategori expert. Siswa expert menyelesaikan masalah fluida statis berdasarkan pendekatan, konsep, prinsip, dan hukum yang sesuai, serta menentukan aplikasi fisika dengan tepat sebagai solusinya. Siswa novice menyelesaikan masalah fluida statis hanya berdasarkan persamaan dan perhitungan matematis tanpa memaknainya, sehingga kerap kali solusi yang diberikan belum tepat.

Penelitian ini juga menemukan lima kesulitan siswa, meliputi (1) kesulitan menjelaskan hubungan massa jenis terhadap besar tekanan pada konsep tekanan hidrostatis, (2) kesulitan menentukan besar tekanan pada rongga dengan luas penampang berbeda pada Hukum Pascal, (3) kesulitan menjelaskan hubungan gaya terhadap luas penampang rongga, (4) kesulitan membedakan besaran yang memengaruhi gaya apung benda pada Hukum Archimedes, dan (5) kesulitan menjelaskan peristiwa terapung, melayang, dan tenggelam pada Hukum Archimedes. 
Hasil penelitian ini memberikan gambaran kepada guru dan peneliti tentang kondisi kemampuan pemecahan masalah dan kesulitan yang masih dialami siswa SMA pada materi fluida statis. Oleh karena itu, perlu dilakukan penelitian lebih lanjut untuk mendesain sebuah pembelajaran yang dapat melatih siswa meningkatkan kemampuan dalam memecahkan masalah. Selain itu, bagi para pendidik diharapkan memahami letak kesulitan-kesulitan siswa sehingga mampu memperbaiki pembelajaran Fisika yang sesuai dalam mengajarkan fluida statis maupun materi fisika lainnya.

\section{DAFTAR RUJUKAN}

Adams, W. K., \& Wieman, C. E. (2015). Analyzing the Many Skills Involved in Solving Complex Physics Problems. American Journal of Physics, 83(5), 459-467.

Argaw, A. S. (2017). The Effect of Problem Based Learning (PBL) Instruction on Students' Motivation and Problem Solving Skills of Physics. EURASIA Journal of Mathematics, Science and Technology Education, 13(3).

Bell, T., Urhahne, D., Schanze, S., \& Ploetzner, R. (2010). Collaborative Inquiry Learning: Models, tools, and challenges. International Journal of Science Education, 32(3), 349-377.

Bunyamin, M. A. H., \& Phang, F. A. (2012). Technological Pedagogical and Content Knowledge among Undergraduate Education Degree Students at Universiti Teknologi Malaysia. Procedia - Social and Behavioral Sciences, 56, 432-440.

Çepni, S., \& Şahin, Ç. (2012). Effect of Different Teaching Methods and Techniques Embedded in the 5E Instructional Model on Students' Learning about Buoyancy Force. Eurasian Journal of Physics and Chemistry Education, 4(2).

Chen, Y., Irving, P. W., \& Sayre, E. C. (2013). Epistemic Game for Answer Making in Learning about Hydrostatics. Physical Review Special Topics - Physics Education Research, 9(1).

Ding, L., Reay, N., Lee, A., \& Bao, L. (2011). Exploring the role of conceptual scaffolding in solving synthesis problems. Physical Review Special Topics - Physics Education Research, 7(2).

Docktor, J., \& Heller, K. (2009). Robust Assessment Instrument for Student Problem Solving. Dalam Proceedings of the NARST 2009 Annual Meeting, Garden Grove, CA (hlm. 1-19).

Docktor, J. L., Dornfeld, J., Frodermann, E., Heller, K., Hsu, L., Jackson, K. A., \& Yang, J. (2016). Assessing Student Written Problem Solutions: A Problem-Solving Rubric with Application to Introductory Physics. Physical Review Physics Education Research, 12(1).

Docktor, J. L., \& Mestre, J. P. (2014). Synthesis of Discipline-Based Education Research in Physics. Physical Review Special Topics - Physics Education Research, 10(2).

Docktor, J. L., Strand, N. E., Mestre, J. P., \& Ross, B. H. (2015). Conceptual problem solving in high school physics. Physical Review Special Topics - Physics Education Research, 11(2). 6

Gök, T., \& Sỳlay, I. (2010). The Effects of Problem Solving Strategies on Students' Achievement, Attitude and Motivation. Latin-American Journal of Physics Education, 4(1), 2.

Goszewski, M., Moyer, A., Bazan, Z., \& Wagner, D. J. (2013). Exploring student difficulties with pressure in a fluid. AIP Conference Proceedings 1513, 154. https://doi.org/10.1063/1.4789675

Hull, M. M., Kuo, E., Gupta, A., \& Elby, A. (2013). Problem-solving rubrics revisited: Attending to the blending of informal conceptual and formal mathematical reasoning. Physical Review Special Topics - Physics Education Research, 9(1).

Koes-H, S., Muhardjito, \& Wijaya, C. P. (2018). Scaffolding for Solving Problem in Static Fluid: A Case Study. AIP Conference Proceedings, 1923(1). https://doi.org/10.1063/1.5019519

Kuczmann, I. (2017). The Structure of Knowledge and Students' Misconceptions in Physics. AIP Conference Proceedings, 1916(1). https://doi.org/10.1063/1.5017454

Kusairi, S., Alfad, H., \& Zulaikah, S. (2017). Development of Web-Based Intelligent Tutoring (iTutor) to Help Students Learn Fluid Statics. Journal of Turkish Science Education (TUSED), 14(2).

Leak, A. E., Rothwell, S. L., Olivera, J., Zwickl, B., Vosburg, J., \& Martin, K. N. (2017). Examining Problem Solving in Physics-Intensive Ph.D. Research. Physical Review Physics Education Research, 13(2). DOI: 10.1103/PhysRevPhysEducRes.13.020101

Lin, S.-Y., \& Singh, C. (2015). Effect of scaffolding on helping introductory physics students solve quantitative problems involving strong alternative conceptions. Physical Review Special Topics - Physics Education Research, 11(2).

Loverude, M. E., Heron, P. R. L., \& Kautz, C. H. (2010). Identifying and Addressing Student Difficulties with Hydrostatic Pressure. American Journal of Physics, 78(1), 75-85.

Minogue, J., \& Borland, D. (2015). Investigating Students' Ideas About Buoyancy and the Influence of Haptic Feedback. Journal of Science Education and Technology, 25(2), 187-202.

Ozcan, O., \& Gercek, C. (2015). What are the Pre-service Physics Teachers' Opinions about Context Based Approach in Physics Lessons? Procedia - Social and Behavioral Sciences, 197, 892-897.

Purnamasari, I., Yuliati, L., \& Diantoro, M. (2018). Kemampuan Pemecahan Masalah dan 1059 Model Mental Siswa pada Materi Fluida Statis. Jurnal Pendidikan: Teori, Penelitian, dan Pengembangan, 3(10), 1299-1302.

Purwanto, R., \& Yuliati, L. (2017). Eksplorasi Kemampuan Pemecahan Masalah Siswa SMA pada Materi Fluida Statis. Prosiding Seminar Pendidikan IPA Pascasarjana UM, 2, 7. 
Radovanović, J., \& Sliško, J. (2013). Applying A Predict-Observe-Explain Sequence in Teaching of Buoyant Force. Physics Education, 48(1), 28.

Ryan, Q. X., Frodermann, E., Heller, K., Hsu, L., \& Mason, A. (2016). Computer Problem-Solving Coaches for Introductory Physics: Design and Usability Studies. Physical Review Physics Education Research, 12(1). DOI:10.1103/PhysRevPhysEducRes.12.010105

Santos, T. C., Pereira, L. N., Ferreira, P. J. G., de Lima, I. B., Vivaldini, T. C., Frugoli, A. D., \& Frugoli, P. A. (2015). A Case Study on The Use of Practical Problem-Solving Activities to Quantitatively Improve Physics Learning in Engineering Education. Proceedings of the 2015International Conference on Operations Excellence and Service Engineering Orlando, Florida, USA, September 10-11, 2015.

Serway, R. A., Jewett, J. W., \& Peroomian, V. (2010). Physics for scientists and engineers with modern physics (Ninth edition). Boston, MA: Brooks/Cole, Cengage Learning.

Sujarwanto, E., \& Hidayat, A., \& Wartono. (2014). Kemampuan Pemecahan Masalah Fisika pada Modeling Instruction pada Siswa SMA Kelas XI. Jurnal Pendidikan IPA Indonesia, 3(1), 65-78.

Urhahne, D., Schanze, S., Bell, T., Mansfield, A., \& Holmes, J. (2009). Role of the Teacher in Computer-supported Collaborative Inquiry Learning. International Journal of Science Education, 32(2), 221-243.

Walker, J., \& Halliday, D. (2011). Fundamentals of Physics (9th ed., extended). Hoboken, NJ: Wiley.

Walsh, L. N., Howard, R. G., \& Bowe, B. (2007). Phenomenographic study of students' problem solving approaches in physics. Physical Review Special Topics - Physics Education Research, 3(2).

Wong, D., Lim, C., Munirah, S., \& Foong, S. K. (2010). Student and Teacher Understanding of Buoyancy. Dalam Physics Education Research Conference.

Yuliati, L., \& Parno. (2018). Exploration of Physics Problem-Solving Skills Within Phenomenon-Based Learning in Senior High School Students (hlm. 97-103). Dipresentasikan pada International Conference on Education. 